\title{
Machine-Made Puzzles and Hand-Made Puzzles
}

\author{
Hiroshi Higashida \\ Graduate School of Human and Environmental Studies, Kyoto University, Japan \\ cheva-teiriacoral.broba.cc
}

\begin{abstract}
Originally puzzles were not for recreation, but serious questions you might be killed if you couldn't solve them. But in modern times, puzzles had become a sort of recreation, decreasing the seriousness and religiousness gradually. Now, the 'rule creators' of puzzles began to attract notice. I, as a rule creator, published a book, Kyoto University Student, Higashida's Puzzles. I'll show several puzzle examples from my inventions. In the puzzle world, the importance of not only making problems but also inventing rules has been insisted. But, unless the mass-producing system of the new rule puzzle is constituted, the rule will disappear at once. It is usually hard to remake puzzles into computer games or videogames. But the puzzle world, where new rules are created in succession, shouldn't be left behind the times.
\end{abstract}

\section{Introduction}

Puzzles have existed since the history of human beings began. They have been and will have been created continuously, changing their shapes or structures variously. Especially since the industrial revolution, puzzles have been invented and produced one after another by gaining 'rules,' and sometimes even have driven the world crazy. These days they are often remade to be sold as computer-games. In fact, puzzle games have a great share of iphone application software and Nintendo DSiWare. This paper studies puzzles as a cultural activity from a view of a puzzle (or its rule) creator, showing some examples of my original ones.

\section{The History of Puzzles with Rules}

Puzzles originated in ancient Greek or ancient Egypt. The description, like a numerical formula, on papyrus in ancient Egypt, or the riddle, 'What goes on four feet, on two feet, and three, but the more feet it goes on the weaker it be?' which the sphinx questioned in the ancient Greek myth, Oedipus Tyrannos, is thought as the oldest one. Mazes, which are often categorized into puzzles, bore religious meaning accompanied by various superstitions all over the world. In ancient Greek, puzzles are sometimes presented in the form of oracles by gods.

Researching the birth of puzzles tells us that originally they were not for recreation, but serious questions you might be killed if you couldn't solve them, represented by the myth Oedipus Tyrannos. Also in the ancient China, Chinese historical document Sengoku Saku says, wire puzzles were assigned a role of ascertaining the degree of 
intelligence of the enemy's king. This fact means that the original seriousness of puzzles was not only in the West, but also in the East. In addition, Many puzzles had born religiousness strongly and been given mysterious rules because of the covered mystery of their answer. 'Magic square' is the representative. Puzzles pursuing this nature reached a climax being inseparable from arts when Rabanus Maurus, a theologian in Karolingische Renaissance, devoted to the empire the puzzle text, $a$ book about praise of sacred cross.

But after that, puzzles had become a sort of recreation, decreasing the seriousness and religiousness gradually. Consequently, puzzles had come to be created by geniuses from among human beings instead of God. The representatives are Sam Loyd and Henry E Dudeney, who are the big two in $19^{\text {th }}$ puzzle world. on the other hand, tangram, whose origin is argued between Japan and China, had formed a new puzzle genre in which everybody could participate as a puzzle creator, by gaining 'rules' that many current puzzles also have. In modern times, when the existence of God who had formed the rules of the world was doubted, puzzle creation had shifted to the task of geniuses or the activity based on given rules; anyway, puzzles became products of human beings.

After the Industrial Revolution, the first triumph as a puzzle with rules was achieved by 'crossword puzzles,' which is even now very popular. It was the dawn of the 'pencil and paper puzzle' which would become the center of the $20^{\text {th }}$ puzzle world. Crossword puzzles, which can be printed on paper, soon spread all over the world because of the cheap cost of production. they were so widespread that Roger Caillois predicted in Les jeux et les hommes that crossword puzzles would decline to end up as a evanescent boom. Now we can say that his prediction was quite wrong. On the contrary, crossword puzzles have cultivated a new puzzle field, in place of the field of mechanical puzzles which had been the center of the puzzle world before then. I predict that crossword puzzles will have been the center of the puzzle world for a while, for they can be easily ported to computer games because they can be shown on a plane.

Japanese puzzle creators are good at pencil and paper puzzles, the genre born of crossword puzzles. 'Number place,' which was born in America and now is the most popular pencil and paper puzzle, was named 'sudoku' in Japan and now even American people call it 'SUDOKU,' which tells Japanese people have grown and developed the puzzle. In addition, because various rules of pencil and paper puzzles are invented in Japan, Japanese puzzles are occupying the attention of the whole world. The Japanese language has an abundant letters combining ideograms and phonograms so is suited for word puzzles by nature. Moreover, the two facts in Edo period that Jingoki, a mathematical book by Mitsuyoshi Yoshida, was a best seller and ordinary people dedicated their achievement of mathematics to shrines, tell that Japanese people have had familiarity with number puzzles since the old days.

Hiroshi Higashida, the author of this paper, is a creator of pencil and paper puzzles. I have not only made puzzles with existent rules, but also developed new rules. I have invented puzzle forms which can be made easily and yet by which puzzle creators can give various expression. In the next chapter, as a puzzle researcher and at the same time as a puzzle creator, I'll tell my theory about puzzles. 


\section{What's Puzzle?}

It's difficult to define 'a puzzle,' but we can approximately decide the category through the comparison with neighboring notions like a quiz or a game. While a quiz is a question to which we can answer right away if we know its answer, a puzzle is a question to which we cannot answer right away even if we know its answer. But for example in a quiz competition using quiz buzzers, though usually called 'quiz,' participants often guess the question sentence which haven't been read completely yet, so the process of thinking is very similar to a puzzle. Conversely, in solving a crossword puzzle, though usually called 'puzzle,' the process of thinking in which solvers think about a word to fill the grid from each clue is often similar to a quiz. Therefore, it is difficult to delineate the boundary between a quiz and a puzzle. If any, there would be gradual difference at most. But it is the undoubted fact that the mechanism of deduction is necessary for solving a puzzle, not for answering a quiz, and it is also the undoubted fact that clear rules are needed to deduce rightly in each puzzle.

A game, like a puzzle, also has clear rules. Violation of rules is regarded as a foul, and if you committed such a foul, you would never be judged to be a winner in both a puzzle and a game. But we can distinguish the two to some extent. While a game has elements which a player cannot handle just as he or her hopes, like chance or opponents, a puzzle doesn't have such elements. The reason why computer games played alone are 'games' is that enemies appear at unpredictable time, and that players cannot manipulate the controller completely just as they hope. Here, we must take into account toys which require cleverness, like cup and ball or mazes with balls. When doing cup and ball, it is difficult to say that we can handle it as we desire. On the other hand, it seems to be less complex to manipulate and to have less intervention of chance than a computer game. So Slocum's classification, which is one of the most well-known classifications of puzzles, contains such toys into 'puzzle,' calling them 'dexterity puzzles.' It is undeniable, however, that such toys are quite similar to games, so it should be discussed more.

Anyway, we can say that a puzzle is a question which challenges people to solve, requires their deduction based on its rules to win, and doesn't depend on chance or other people's action. You cannot defy rules which are, so to speak, 'absolute authority.'

Puzzle creators, not only solvers, mustn't defy rules, either. Especially, in puzzles which can be made easily one after another like crossword puzzles, we might say that rules control the creators and rules even form the works. It is a curious paradox that puzzles, which seem to be independent of the control of chance or other people, are in fact already controlled at the stage of creation by rules someone made. Rules which appear in the $20^{\text {th }}$ century uncovered this paradox in the puzzle world and thereby altered nature of puzzle creators.

\section{I, as a Rule Creator}

In $20^{\text {th }}$ century, numerous creators of pencil and paper puzzles appeared. This genre, from crossword puzzles to Sudoku, shows us various scenes, because rules of a puzzle 
by which creators can make it easily are made one after another. Creators can express their creativity in their works there, displaying their originalities obeying existent rules, just as haiku poets create their works under the rule of seventeen syllables in the 5-7-5 form.

At the same time, the 'rule creators' of puzzles began to attract notice. Some puzzle magazines positively accept contributions of puzzle rules. Now rules in themselves are coming to be recognized to be valuable. In 2010, these two puzzle books were published in succession in Japan; Puzzle Brain, by Naoki Inaba, Odysseus, in which 24 sorts of new puzzles are included, and Kyoto University Student, Higashida's Puzzles, by Hiroshi Higashida, Kadokawa Gakugei, in which 18 sorts of new puzzles are included. Before, there weren't any books in which only puzzles with new rules by one author are collected. These two books tell us the importance of invention of rules in current puzzle world.

In one of the two, my Kyoto University Student, Higashida's Puzzles, eight sorts of puzzles which depend on Japanese language and ten sorts of puzzles which don't depend on Japanese language are included. The former puzzles don't have international penetration because we cannot solve them if we don't know Japanese characters or vocabularies. But we can rediscover Japanese nature through solving them and seeing Japanese abundant expressions with characters from various angles. By contrast, the latter puzzles can be played by people all over the world since numbers or signs are used in them. The worldwide boom in Sudoku proves that. Certainly, crossword puzzles, which depend on language, seem to spread in the world. But for example in China, where kanji is used, it is hard to make them, so they don't have perfect penetration just as it is. On the other hand, puzzles which don't depend on language have demerits, for expression creators can give is limited and originality they can display is hard to see in those puzzles.

I've invented rules of both language-dependent and language-independent puzzles. I might be a 'rule creator,' as opposed to a 'puzzle creator' who makes puzzles under existent rules. Especially, there weren't many eager rule creators of languagedependent puzzles. Inaba's book I've referred before, without exception, consists of only language-independent puzzles. There are few people who can invent both of the two sorts one after another. This is because the two require different way of thinking; language-dependent puzzles are intuitive, while language-independent puzzles are logical. So, working of many puzzle creators inclines to one of them. My today's working as a 'rule creator' reaps great benefits from my lucky nature of being able to enjoy both puzzles.

\section{Higashida Puzzles}

Now, I'll show several puzzle examples from my inventions. From my book, Kyoto University Student, Higashida's Puzzles, first, I'll introduce a few languageindependent puzzles. In room light, you must put a light (a circle) in each room divided by bold lines (Fig.1). The numbers on the outside of the grid indicate how many lights must be put in that row or column. In easy problems, you'll find numbers like 0 or 7 , which tell clearly whether there are lights or not in that row and column, and from there you can proceed. In difficult problems, you'll have to seek a cell 
where a light is certainly or never placed, wherever a light is put in another $1 \times \mathrm{n}$ room. This puzzle is comparably simple, for there are few more difficult solutions. If I had wanted the puzzle more complex, I would have added this rule, "no two lights can be in adjacent cells.' But in fact I didn't, and retained the simplicity. This is because I wanted to avoid increasing fatigue of solvers by adding one rule. Though room light is the simplest puzzle, even then it maintains the essence of the real attraction of mathematical puzzles. Here are two problems, one is easy, and the other is difficult. Please challenge them.
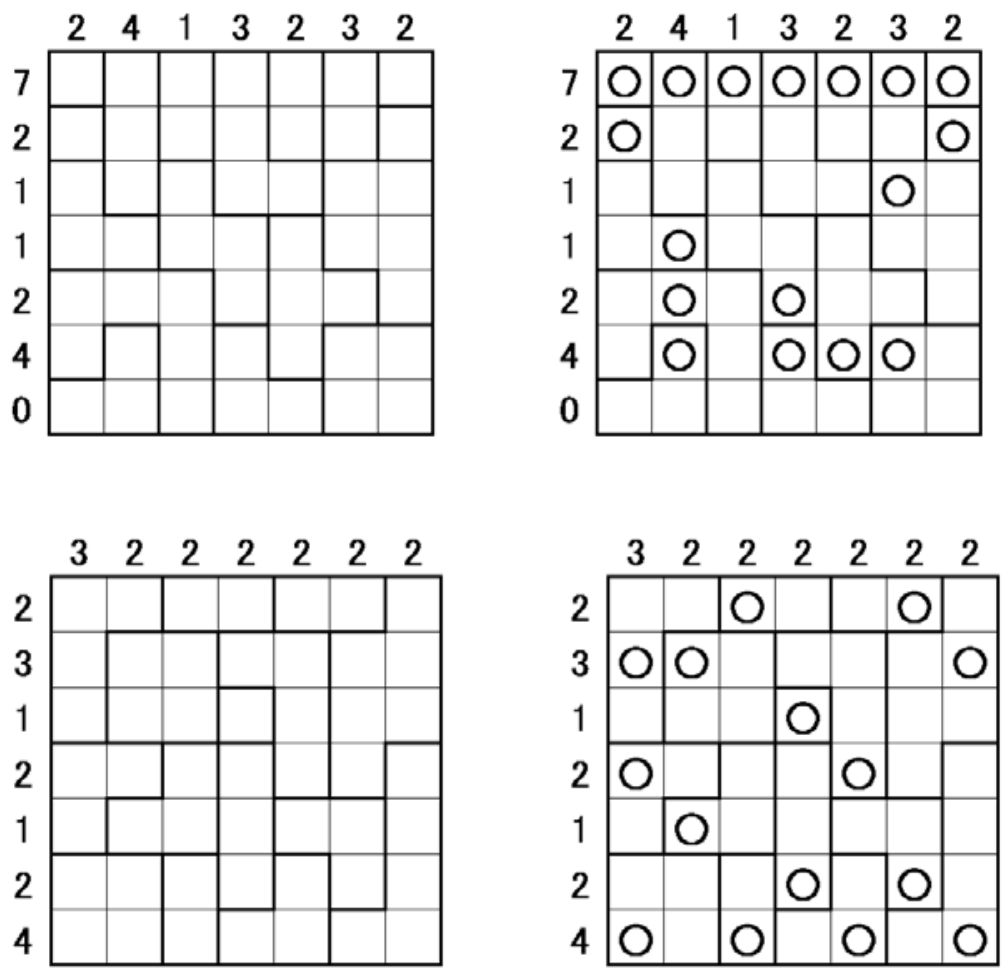

Fig. 1. left: problem right: solution

In 'Alphabet block,' you must divide the grid into blocks which contain four cells, provided that different alphabets mustn't be included in one block (Fig.2). Though this puzzle is also quite simple, the rule deciding how many cells each block has effectively enables us to create difficult problems. In this puzzle too, if I had added the rule, "no two blocks which contain the same alphabet can touch, except at corners,' the puzzle would have become more complex. But actually I didn't, under this concept, 'the simpler the rule is, the better.' Even then we can create more difficult problems of this puzzle than room light. 

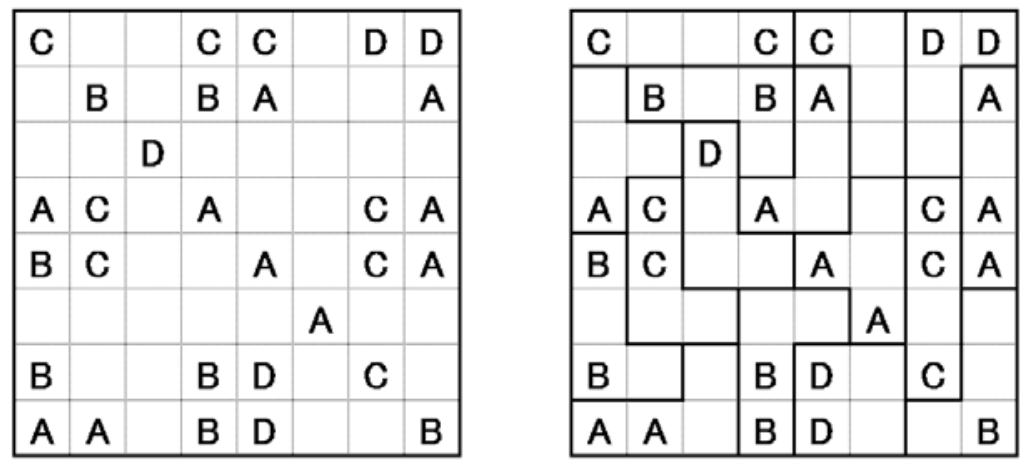

Fig. 2. left: problem right: solution

As the last example of language-independent puzzles, I'll introduce 'connect number,' which was remade into Nintendo DSi software later. In this puzzle, you must connect all pairs of numbers with continuous lines, provided that you mustn't cross lines (Fig.3). The idea, to link pairs, has existed in puzzle world since before I was born. 'Number link' is one of the forms of the idea, which has been published in the books or magazines of Nikoli, Japanese puzzle publishing company. But in number link, the addition of the rule, 'you can draw only one line on a cell,' makes the puzzle too difficult for puzzle beginners to solve (Fig.4). So I tried to remove 'grid,' which had long fixed pencil and paper puzzle world since the invention of crossword puzzle. After considering various possibilities, I discovered the way of adding the place where lines cannot pass (wall). Thereby in connect number, while the grid rules are removed, we can create from easy problem to difficult. This puzzle will please all people. For beginners, the rules are easy, and for experts, drawing lines freely is fresh.
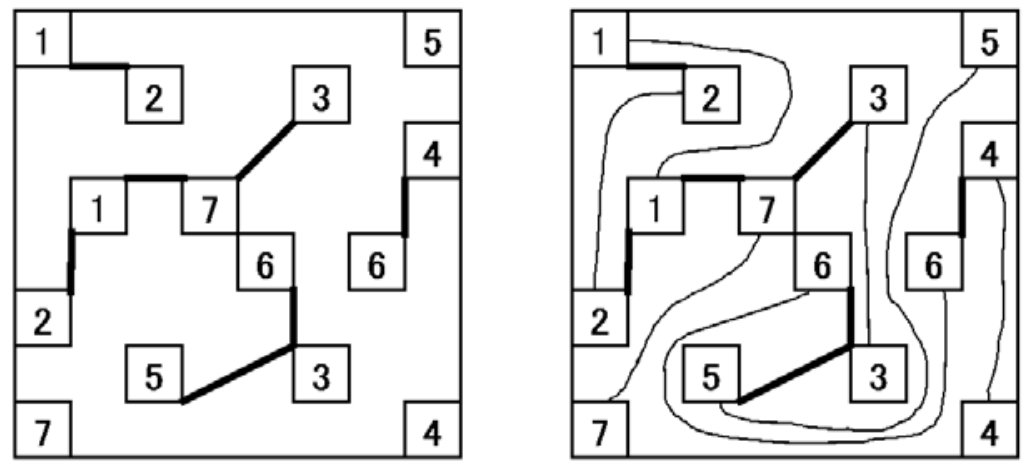

Fig. 3. left: problem right: solution 

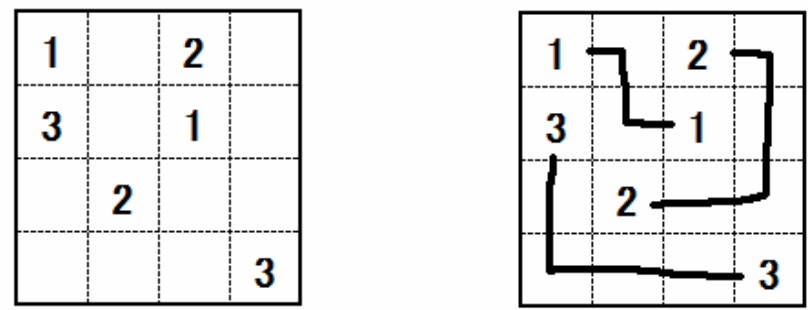

Fig. 4. left: problem right: solution

This puzzle was remade into Nintendo DSi software, as I wrote before (Fig.5). Pencil and paper puzzles are suitable for Nintendo DS which we manipulate with a touch pen, and this puzzle is no exception. But in the game edition, it was altered in a few points: first, to change numbers into pictures; second, to set a time limit; finally, to allow more than one solution. The reason of first alteration is that at the game solvers perhaps think they must connect from 1 in order by misunderstanding. The second is to enhance solvers' seriousness to the game. A problem with plural solutions, the final alternation, is allowed because the game machine can judge whether solvers finished or not and so they can be sure of their completion. This alternation for the game produced a new way of playing, playing by finding another solution that is effective for speed-up.
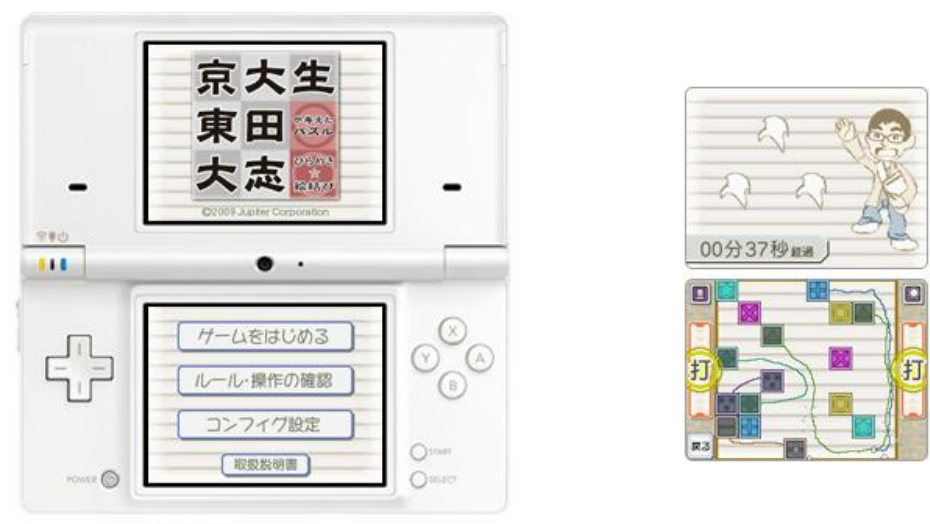

Fig. 5.

Next, I'll introduce my language-dependent puzzles. See 'compound word maze' (Fig.6). In Japanese language, many compound words made up of four kanji are used, and they often have a special meaning like proverbs. In this puzzle, you must go from the start to the goal, picking up just four kanji to constitute such a compound word. In this puzzle, puzzle creators can control the level of their problems, by increasing or decreasing tricky kanji and obstacle walls. Also, Japanese people's name often consists of four kanji, so the rule can be altered to constitute the name of historical 
figure, for example. Because the structure of mazes is not so complex, this puzzle can appear on TV programs. In fact, I have shown this puzzle on TV a few times.
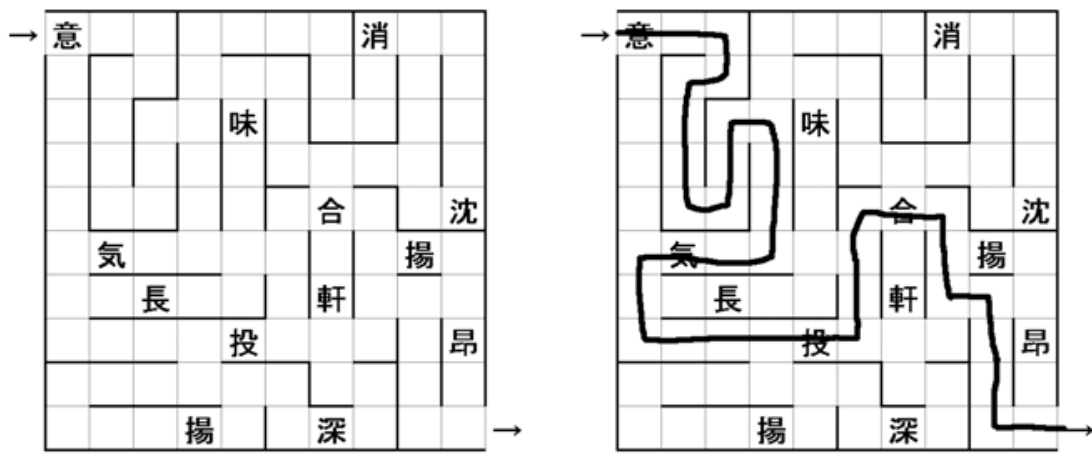

Fig. 6. left: problem right: solution

The last puzzle I introduce is 'kanji katakana cohabitation.' See fig.7. Japanese is a language which has numerous characters, kanji, katakana, and hiragana, used according to circumstances. Above all, words compounded of kanji and katakana are mixed words, in which coexist words of Japanese origin (written in kanji) and words of foreign origin (written in katakana), and interest puzzle creators. To take such words into my puzzle, I decided to adopt a rule of 'number crossword' which originated in English language sphere. 'Number crossword' is a sort of crossword puzzle in which solvers fill the grid under this rule: 'each letter is replaced by a number.' It is unexpected that this rule is suited for kanji-katakana words, but certainly it is. Consequently, the first puzzle of kanji-katakana words in Japan (of course in the world) was completed. The puzzle form in which only kanji is appearing and katakana should be filled in spaces is quite unique.

$$
\begin{aligned}
& \text { 冬季 } \frac{-}{15}-\frac{-}{5}-\frac{7}{7}-\frac{7}{15} \frac{7}{9} \text { 旅行 記 } \\
& \text { 油性 } \frac{7}{14}-\frac{1}{13}-\quad \frac{7}{13} \frac{7}{16} \frac{7}{11} \text { 地 形 チェック表 }
\end{aligned}
$$

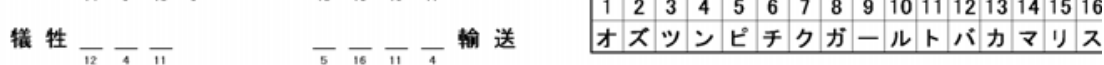

$$
\begin{aligned}
& \text { 大 } \frac{15}{15}-\frac{7}{9}-\frac{7}{13} \text { 砲答 } \\
& \text { 粉 } \frac{-7}{6}-\frac{1}{2}-\frac{7}{7} \text { 転 } \\
& \frac{7}{7}-\frac{7}{14}-\frac{7}{7} \text { 車 }-\frac{7}{14} \text { 線 } \\
& \frac{7}{14}-\frac{7}{7} \text { 経斎学 } \frac{7}{13} \text { 等 } \\
& \text { チェック表 } \\
& \begin{array}{|l|l|l|l|l|l|l|l|l|l|l|l|l|l|l|l|}
\hline 1 & 2 & 3 & 4 & 5 & 6 & 7 & 8 & 9 & 10 & 11 & 12 & 13 & 14 & 15 & 16 \\
\hline
\end{array}
\end{aligned}
$$

Fig. 7. left: problem right: solution 


\section{Conclusions}

Thus, in the puzzle world, the importance of not only making problems but also inventing rules has long been insisted. But, unless the mass-producing system of the new rule puzzle is constituted, the rule will disappear at once. One of the reasons why Sudoku have driven the world crazy is that creators can make problems one after another by computer programs. But it is often said that problems by computers are inferior to that by hand. Mass production of problems of inferior quality may ruin the attraction of puzzles. The auto-making programs should be improved. Today, the system which has advantages of both computers and hand-made has been considered. These new ways of making puzzles are expected to become a trigger of inventing new rules.

It is usually hard to remake pencil and paper puzzles into computer games or videogames, because of the restriction of their hardware. Above all, to remake kanji puzzles, kanji recognition systems of the hardware are still underdeveloped. While digitization of books is developing rapidly, the puzzle world, where new rules are created in succession, shouldn't be left behind the times. Just like the case that 'connect number' was digitized, the pursuit of pleasure only in electronic mediums should be aimed.

Movement, order, and time are hard to realize on paper. In electronic medium, puzzles which contain such elements can be realized. If the medium changes, the restriction on making rules also changes. The puzzle rules only for computers or videogames will show us the new puzzle world in the future. The demand for 'rule creator' is certainly increasing now.

\section{References}

1. Akiyama, H.: Chinese Rings Book, Shinkigensha (2003) (in Japanese)

2. Akiyama, H.: Picture and Shape Puzzles Book, Shinkigensha (2005) (in Japanese)

3. Caillois, R.: Les jeux et les hommes. Gallimard (1967)

4. Danesi, M.: The Liar Paradox and the Towers of Hanoi. Wiley, Chichester (2004)

5. Higashida, H.: Kyoto University Student, Higashida's Puzzles. Kadokawa Gakugei Publisher (2010) (in Japanese)

6. Inaba, N.: Puzzle Brain, Odysseus (2010) (in Japanese)

7. Shibata, T., Tanikawa, S., Yagawa, S.: World Riddles Encyclopedia, Taishukan (1984) (in Japanese)

8. Slocum, J., Botermans, J.: Puzzles Old and New, Washington (1986)

9. Takagi, S.: Puzzle Encyclopedia, Kodansha (1985) (in Japanese)

10. Takagi, S.: Play Puzzle, Heibonsha (1981) (in Japanese)

11. Takagi, S.: Play Puzzle 2, Heibonsha (1982) (in Japanese)

12. Zumthor, P.: Langue Texte Énigme. Editions du Seuil, Paris (1975) 